\title{
Deep Quench: An Expanded Dynamic Range for Protein Kinase Sensors
}

\author{
Vyas Sharma, Richard S. Agnes, and David S. Lawrence \\ Department of Biochemistry, The Albert Einstein College of \\ Medicine, 1300 Morris Park Ave., Bronx, New York 10461
}

\section{Supporting Information}

\section{Experimental section}

General reagents and solvents were purchased from Fisher or Aldrich. CLEAR Rink amide resin and Fmoc-2,6-dioxoaminooctanoic acid, HCTU [1 H-benzotriazolium 1[bis(dimethylamino)methylene]-5-chloro-,hexafluorophosphate (1-),3-oxide], and $\mathrm{HOBt}-\mathrm{Cl}$ (6chloro-1-hydroxy-1H-benzotriazole) purchased from Peptides International (Louisville, KY). Fmoc-ß-Ala-OH, Fmoc-aminobutyric acid, Fmoc-aminovaleric acid, Fmoc-aminohexanoic acid, and Fmoc-aminooctanoic were purchased from Advanced Chem Tech (Louisville, KY). Fmoc-Dap(Mtt)-OH was purchased from Novabiochem (La Jolla, CA). PKA murine catalytic subunit plasmid and the GST-14-3-3 $\tau$ plasmid were generous gifts from Dr. Susan Taylor and Dr. Alistair Aitken, respectively.

Synthesis of Peptide Libraries. Peptides were synthesized by standard solid phase synthesis using Fmoc chemistry. The Fmoc protecting group was removed with $20 \%$ piperidine in dimethylformamide (DMF) (1x5 min, 1x20 min). Sequential coupling of Fmoc protected amino acids was achieved with 3 equiv. Fmoc amino acid, 3 equiv. HCTU, 3 equiv. $\mathrm{HOBt}-\mathrm{Cl}$, and 6 equiv. diisopropylethylamine (DIPEA). Completion of each reaction was monitored with the Kaiser and chloranil tests. Resins were washed between steps with DMF, isopropyl alcohol (IPA), and DCM. For peptides P1 - P5, the free N-terminal Gly ${ }^{1}$ was acylated with 20 equiv. of acetic anhydride in dissolved in 1:1 pyridine:DMF. The 4methyltrityl protecting group on Dap(Mtt) was orthogonally removed using $5 \%$ trifluoroacetic acid (TFA) and 5\% triisopropylsilane (TIPS) in DCM (5 min incubation). The resulting free $\beta-$ amine was acylated with 3 equiv. 1-pyreneacetic acid in DMF containing 3 equiv. HCTU, 3 equiv. $\mathrm{HOBt}-\mathrm{Cl}$, and 6 equiv. of DIPEA. The free $\mathrm{N}$-termini of peptides P6 - P11 were directly acylated with 1-pyreneacetic acid following the Fmoc deprotection of terminal ß-alanine (BAla), aminobutyric acid (Abu), aminovaleric acid (Ava), aminohexanoic acid (Ahx), aminooctanoic acid (Aoc), and amino-3,6-dioxoaminooctanoic acid (miniPEG ${ }^{\mathrm{TM}}$ ) groups, respectively. The remaining orthogonal protecting groups were removed and the peptides cleaved from their resins with 95\% TFA, 5\% water, 5\% TIPS (3 hr). The peptides were isolated via filtration of the resin, precipitation with ice-cold diethyl ether, and centrifugation. The precipitates were air dried and purified by reverse-phase HPLC using a linear gradient (3\% - 40\% acetonitrile in water with $0.1 \%$ TFA over $40 \mathrm{~min})$. The peak corresponding to the 
desired peptide was collected, frozen, and lyophilized. The resulting white, flocculent peptides were characterized by electrospray ionization mass spectrometry: P1 Ac-Gly-ArgThr-Gly-Arg-Arg-Phe-Ser-Dap(Pyr)-Pro-amide (m/z calculated 1403.72, found 1403.80); P2 Ac-Gly-Arg-Thr-Gly-Arg-Arg-Dap(Pyr)-Ser-Tyr-Pro-amide ( $\mathrm{m} / \mathrm{z}$ calculated 1419.72, found 1419.60); P3 Ac-Gly-Arg-Thr-Dap(Pyr)-Arg-Arg-Phe-Ser-Tyr-Pro-amide (m/z calculated 1507.75, found 1509.47); P4 Ac-Gly-Arg-Dap(Pyr)-Gly-Arg-Arg-Phe-Ser-Tyr-Pro-amide (m/z calculated 1463.72, found 1464.87); P5 Ac-Dap(Pyr)-Arg-Thr-Gly-Arg-Arg-Phe-Ser-Tyr-Proamide (m/z calculated 1507.75, found 1509.93); P6 Pyr-ßAla-Gly-Arg-Thr-Gly-Arg-Arg-PheSer-Tyr-Pro-amide (m/z calculated 1507.75, found 1509.47); P7 Pyr-Abu-Gly-Arg-Thr-GlyArg-Arg-Phe-Ser-Tyr-Pro-amide (m/z calculated 1521.76, found 1523.80); P8 Pyr-Ava-GlyArg-Thr-Gly-Arg-Arg-Phe-Ser-Tyr-Pro-amide (m/z calculated 1535.78, found 1537.40); P9, Pyr-Ahx-Gly-Arg-Thr-Gly-Arg-Arg-Phe-Ser-Tyr-Pro-amide (m/z calculated 1549.79, found 1551.60); P10 Pyr-Aoc-Gly-Arg-Thr-Gly-Arg-Arg-Phe-Ser-Tyr-Pro-amide (m/z calculated 1577.83, found 1578.73); P11 Pyr-miniPEG ${ }^{\text {TM}}$-Gly-Arg-Thr-Gly-Arg-Arg-Phe-Ser-Tyr-Proamide $(\mathrm{m} / \mathrm{z}$ calculated 1582.76 , found 1583.73$)$.

Identification of Lead Quencher Dyes. The concentration of peptides P1 - P11 was adjusted to $50 \mu \mathrm{M}$ based on the molar excitation coefficient of $22,000 \mathrm{M}^{-1} \mathrm{~cm}^{-1}$ at $345 \mathrm{~nm}$. The concentrations of 47 dyes were adjusted to $50 \mu \mathrm{M}$ by weight. The peptides were screened against the dyes on 96 well plates using an HTS 7000 Bio Assay Reader (Perkin Elmer) with $340 \mathrm{~nm}$ excitation filter and $380 \mathrm{~nm}$ emission filter, a setting of $100 \mu$ s integration time, and 5 flashes. Each well contained $5 \mu \mathrm{M}$ peptide and $5 \mu \mathrm{M}$ dye in $50 \mathrm{mM}$ Tris- $\mathrm{HCl}$ at $\mathrm{pH}$ 7.5. Dyes that resulted in the greatest degree of fluorescence quenching were noted.

Chart S1. Lead quencher dyes of pyrene peptides P1 - P11.

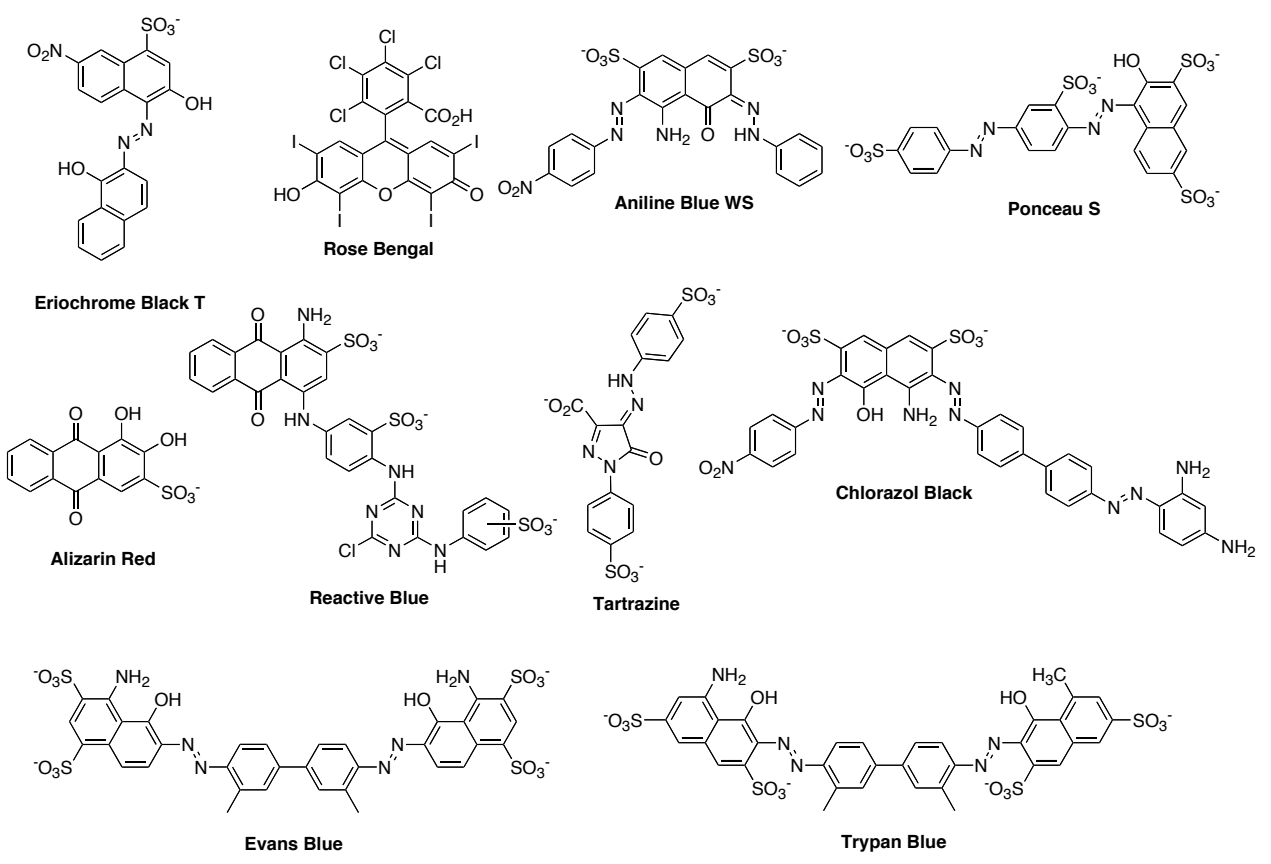


Table S1. Library of Dyes

\begin{tabular}{l|c} 
D1 & Acid Green 27 \\
D2 & Acid Blue 40 \\
D3 & Evans Blue \\
D4 & Acid Alizarin Violet N \\
D5 & Acid Blue 80 \\
D6 & Reactive Blue 2 \\
D7 & N,N-dimethylnitrosoaniline \\
D8 & Cresol Red \\
D9 & Phenol Red \\
D10 & Methyl Orange \\
D11 & Bromophenol Blue \\
D12 & BUFFER \\
D13 & Xylene Cyanol FF \\
D14 & Disperse Yellow 3 \\
D15 & Ethyl Orange \\
D16 & Methylene Blue \\
D17 & Brilliant Blue R \\
D18 & Eriochrome Black T \\
D19 & Alizarin Red \\
D20 & Malachite Green oxalate \\
D21 & Phenolphthalein \\
D22 & Carminic Acid \\
D23 & Nuclear Fast Red \\
D24 & Acid Fuchsin \\
D25 & Acridine Orange \\
D26 & Acridine Yellow G \\
D27 & Aniline Blue WS \\
D28 & Azure A \\
D29 & Azure B bromide \\
D30 & Basic Fuchsin \\
D31 & Bismark Brown Y \\
D32 & Brilliant Yellow \\
D33 & Bromocresol Purple \\
D34 & Chlorazol Black E \\
D35 & Chlorophenol Red \\
D36 & Chrysoidine Y \\
D37 & Erythrosin \\
D38 & Ethyl Violet \\
D39 & Naphthol Blue Black \\
D40 & Methylthymol Blue \\
& \\
&
\end{tabular}




\begin{tabular}{l|c} 
D41 & Methyl Violet \\
D42 & Ponceau S \\
D43 & Rose Bengal \\
D44 & Rosolic Acid \\
D45 & Safranin O \\
D46 & Serva Violet 49 \\
D47 & Tartrazine \\
D48 & Trypan Blue
\end{tabular}


Acquisition of Apparent $K_{D}$ Values for Lead Quencher Dyes with Peptide P2. Varying concentrations of 10 dyes, ranging from $0.5-500 \mu \mathrm{M}$, were added to $5 \mu \mathrm{M}$ pyrene-labeled P2 peptide in $100 \mathrm{mM}$ Tris $\mathrm{HCl}$ pH 7.5 buffer (96 well plates). A Spectra Max Gemini EM plate reader (Molecular Devices) was used for fluorescence measurements ( $\lambda_{\mathrm{ex}}=342 \mathrm{~nm}$ and $\left(\lambda_{\text {em }}=380 \mathrm{~nm}\right)$. Correction for the inner filter effect was made using the antilogarithm of the effective optical density times half the width of the fluorescence well as previously reported (Clin. Chem 23 (12) 2292-2301, 1977). Molar absorbtivities ( $\varepsilon_{342}$ and $\varepsilon 380$ ) were calculated from single absorbance spectra at a [dye] $=7.81 \mu \mathrm{M}$. For all dyes at concentrations below $10 \mu \mathrm{M}$, the inner filter effect required a correction of less than $10 \%$ in the measured fluorescence. However, at higher concentrations, the effect became significant for strongly absorbing dyes. After correcting for the inner filter effect, the percentage of quench was plotted against the concentration of the dye. A nonlinear regression analysis fit of the data to the rectangular hyperbola model using the Sigma Plot version 8.02 software was used to obtain apparent $K_{\mathrm{D}}$ values.

Table S2. Apparent $K_{\mathrm{D}}$ Values of Lead Quenchers with Peptide P2.

\begin{tabular}{|c|c|c|}
\hline \multicolumn{2}{|c|}{ Quencher Dye } & Apparent $\boldsymbol{K}_{\mathbf{D}}(\boldsymbol{\mu M})$ \\
\hline D3 & Evans Blue & $2.8 \pm 0.8$ \\
D6 & Reactive Blue & $19.6 \pm 3.4$ \\
D18 & Eriochrome Black & $14.3 \pm 3.3$ \\
D19 & Alizarin Red & $7.3 \pm 2.5$ \\
D27 & Aniline Blue WS & $18.1 \pm 2.6$ \\
D34 & Chlorazol Black E & $7.7 \pm 1.5$ \\
D42 & Ponceau S & $11.2 \pm 2.7$ \\
D43 & Rose Bengal & $7.5 \pm 1.6$ \\
D47 & Tartrazine & $15.0 \pm 2.1$ \\
D48 & Trypan Blue & $11.9 \pm 3.6$ \\
\hline
\end{tabular}

Acquisition of apparent $K_{D}$ values for lead quencher/peptide pairs were performed as described above and are reported in the manuscript. In addition, the apparent $K_{\mathrm{D}}$ value for the phosphorylated P5 peptide AcDap(Pyr)RTGRRFS $\left(\mathrm{PO}_{3}{ }^{2-}\right) \mathrm{YP}$-amide with Rose Bengal is $210 \pm 40 \mathrm{nM}$, slightly tighter than that found for the unphosphorylated AcDap(Pyr)RTGRRFSYP-amide/Rose Bengal pair (400 $\pm 30 \mathrm{nM})$. 
Figure S1. Percent Fluorescent Quenching of Peptide P2 As A Function of Concentration of Dyes 1 - 10.
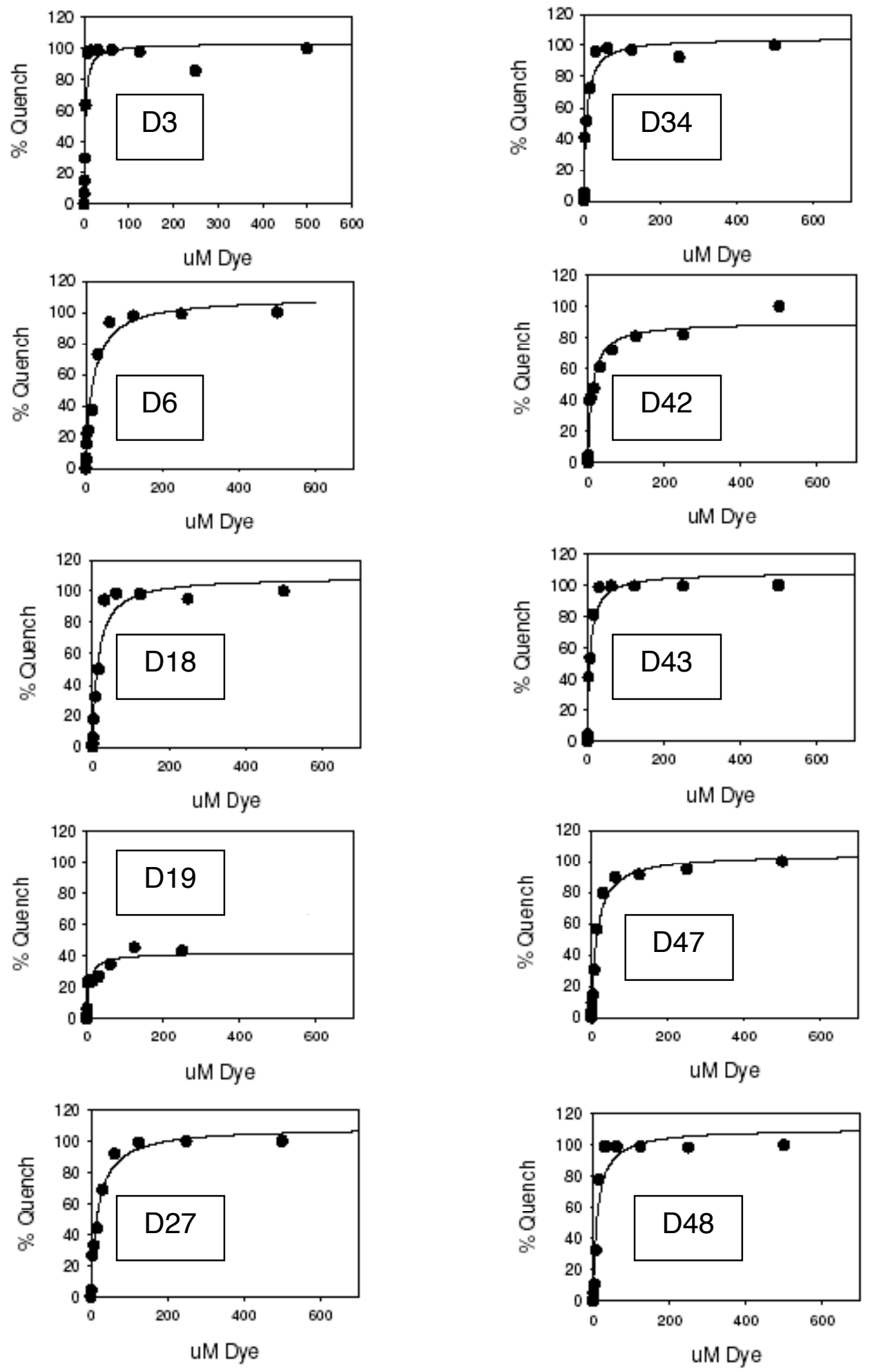
Figure S2. Percent Fluorescent Quenching of pyrene fluorescence in (A) peptide P5 with Rose Bengal dye (red) and peptide P9 with Aniline Blue WS dye (cyan), and (B) phosphorylated peptide P5 and Rose Bengal.
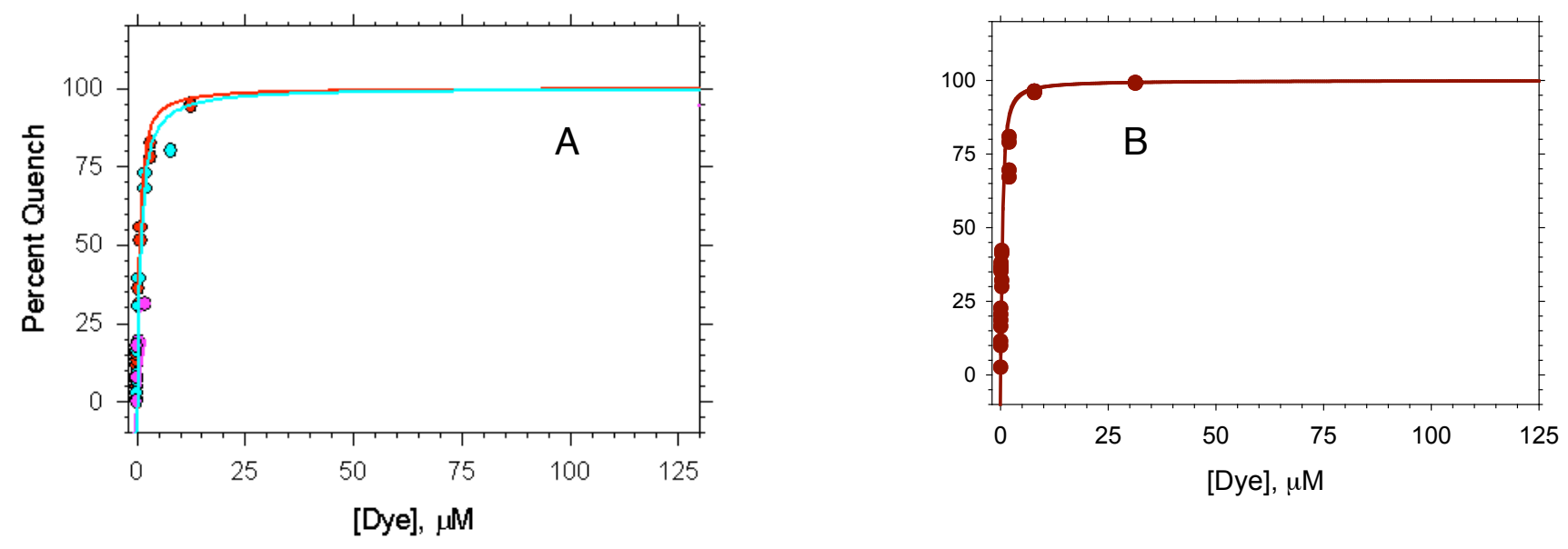
Screening of Lead Quenching Dyes 1 - 10 with Peptides P1 - P11. PKA-catalyzed phosphorylation was initiated by addition of $25 \mu \mathrm{L}$ of $100 \mathrm{nM}$ PKA enzyme to the following solution: $25 \mu \mathrm{L} 50 \mu \mathrm{M}$ fluorescent peptide substrates (P1 - P11), $25 \mu \mathrm{L} 20 \mathrm{mM}$ DTT, $25 \mu \mathrm{L} 10$

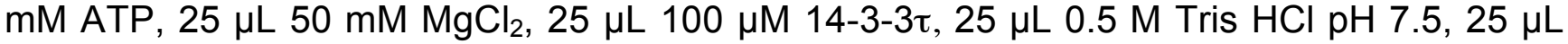
dye (10 dyes at 4 concentrations, $0.25 \mathrm{mM}, 0.5 \mathrm{mM}, 1.25 \mathrm{mM} 2.5 \mathrm{mM}$ and no dye as a control) to give final volume of $250 \mu \mathrm{L}$. The concentrations per well were: $10 \mathrm{nM}$ PKA, $5 \mu \mathrm{M}$

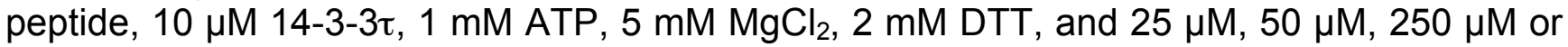
$500 \mu \mathrm{M}$ each of 10 different lead dyes in $50 \mathrm{mM}$ Tris at pH 7.5 buffer. The HTS 7000 Bio Assay Reader was set in kinetic mode to monitor the progress of reaction (340 nm excitation filter, $380 \mathrm{~nm}$ emission filter, $100 \mu \mathrm{s}$ and 5 flashes).

Table S3. Control Experiment: Phosphorylation-induced Change in Fluorescence of Pyrenelabeled peptides P1 - P11 in the Absence of Quenching Dye.

\begin{tabular}{|c|c|c|}
\hline \multicolumn{2}{|c|}{ Pyrene-labeled Peptide } & $\begin{array}{c}\text { \% Fluorescence } \\
\text { Enhancement }\end{array}$ \\
\hline P1 & Ac-GRTGRRFSDap(Pyr)P-amide & 0 \\
P2 & Ac-GRTGRRDap(Pyr)SYP-amide & $51 \%$ \\
P3 & Ac-GRTDap(Pyr)RRFSYP-amide & $19 \%$ \\
P4 & Ac-GRDap(Pyr)GRRFSYP-amide & $40 \%$ \\
P5 & Ac-Dap(Pyr)RTGRRFSYP-amide & $64 \%$ \\
P6 & Pyr-BAla-GRTGRRFSYP-amide & $49 \%$ \\
P7 & Pyr-Abu-GRTGRRFSYP-amide & $47 \%$ \\
P8 & Pyr-Ava-GRTGRRFSYP-amide & $31 \%$ \\
P9 & Pyr-Ahx-GRTGRRFSYP-amide & $48 \%$ \\
P10 & Pyr-Aoc-GRTGRRFSYP-amide & $39 \%$ \\
P11 & Pyr-miniPEG & $38 \%$ \\
\hline
\end{tabular}


Beer's Law Analysis. The fluorescence intensities of different concentrations of phosphorylated P5 peptide (ranging from 0 to $1 \mu \mathrm{M}$ and incubated with $10 \mu \mathrm{M} 14-3-3 \tau$ and $100 \mathrm{mM}$ Tris $\mathrm{HCl} \mathrm{pH} \mathrm{7.5)} \mathrm{were} \mathrm{determined} \mathrm{in} \mathrm{the} \mathrm{presence} \mathrm{of} 12.5 \mu \mathrm{M}$ Rose Bengal. The intensities were plotted against the peptide concentration and the data fit to a straight line (pink). The fit of the data with background correction (gray) is shown as a dotted line. The background was acquired by using a sample that had all the assay components except the fluorophore-peptide by using the "Acquire Background" mode in FeliX software (Photon Technology version 1.42). This background intensity was automatically subtracted from subsequent measurements by the software.

Figure S3. Fluorescence as a function of [peptide P5] before (magenta) and after (grey dotted) background correction.

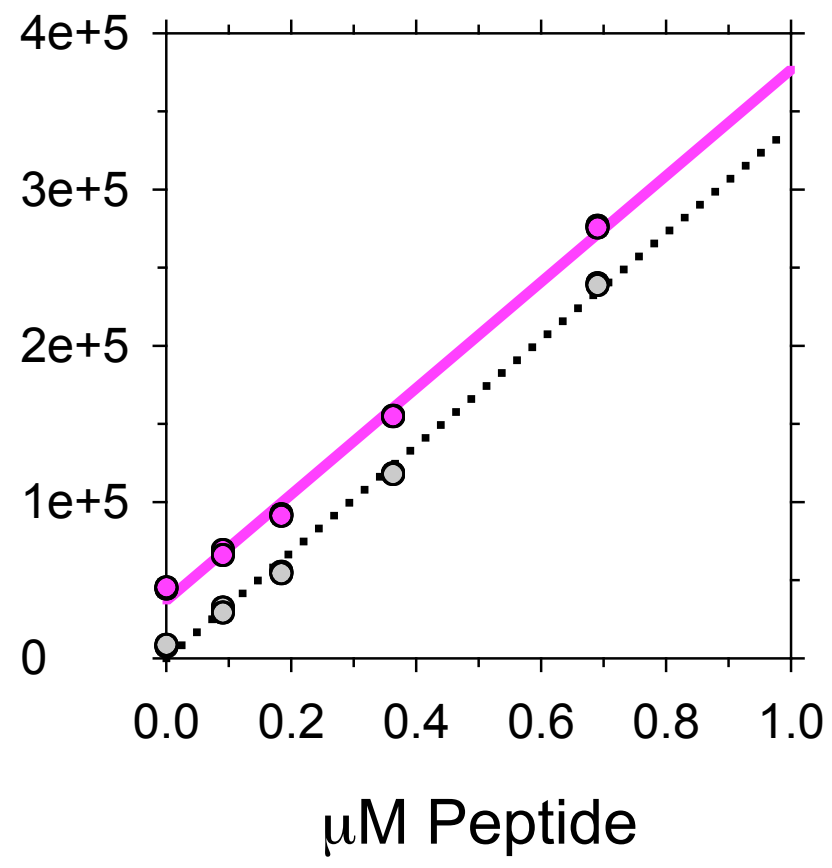


Acquisition of $\boldsymbol{K}_{\boldsymbol{m}}$ and $\boldsymbol{V}_{\max }$ values: Phosphorylation dependent increase in pyrene fluorescence intensity of peptides P2, P5 and P9 were monitored on a Photon Technology QM-1 spectrofluorimeter at $30{ }^{\circ} \mathrm{C}$ using $343 \mathrm{~nm}$ excitation wavelength, $380 \mathrm{~nm}$ emission wavelength, and an $8 \mathrm{~nm}$ slit-width. After equilibration of different concentrations of the

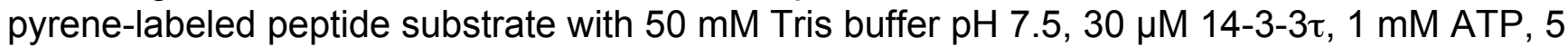
$\mathrm{mM} \mathrm{MgCl} 2,2 \mathrm{mM}$ DTT, for $10 \mathrm{~min}, 10 \mathrm{nM}$ enzyme was added and the reaction progress curves obtained. Reaction rates were determined from the slope under conditions where 5 $8 \%$ substrate had been converted to product in duplicate. The resulting slopes (initial velocity, $v_{0}$ ) for each of the progress curves were plotted versus the concentration of substrate. A nonlinear regression analysis was used to fit the data to the rectangular hyperbola model using the Sigma Plot version 8.02 software.

Assay Dependence on 14-3-3 $\tau$ P.hosphorylation-dependent increase in pyrene fluorescence intensity of peptide P5, in the presence and absence of 14-3-3 $\tau$, was monitored on a Photon Technology QM-1 spectrofluorimeter at $30^{\circ} \mathrm{C}$ using $343 \mathrm{~nm}$ excitation wavelength, $380 \mathrm{~nm}$ emission wavelength with an $8 \mathrm{~nm}$ slit-width. $5 \mu \mathrm{M}$ pyrene-labeled peptide substrate P5 was pre-incubated in $25 \mu \mathrm{M}$ Rose Bengal, $5 \mathrm{mM} \mathrm{MgCl}_{2}, 2 \mathrm{mM}$ DTT, 1.4 $\mu \mathrm{M}$ PKA, and $50 \mathrm{mM}$ Tris buffer $\mathrm{pH} 7.5$, in the presence (red), and absence (gray), of $30 \mu \mathrm{M}$ 14-3-3 $\tau$, at $30{ }^{\circ} \mathrm{C}$ for $5 \mathrm{~min}$. After $1 \mathrm{~min}, 1 \mathrm{mM}$ ATP was added and the reaction progress followed. In the absence of $14-3-3 \tau$ (gray), no change in fluorescence intensity was observed.

Figure S4. PKA-induced fluorescence change of the Rose Bengal/peptide P5 pair in the

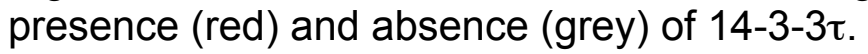

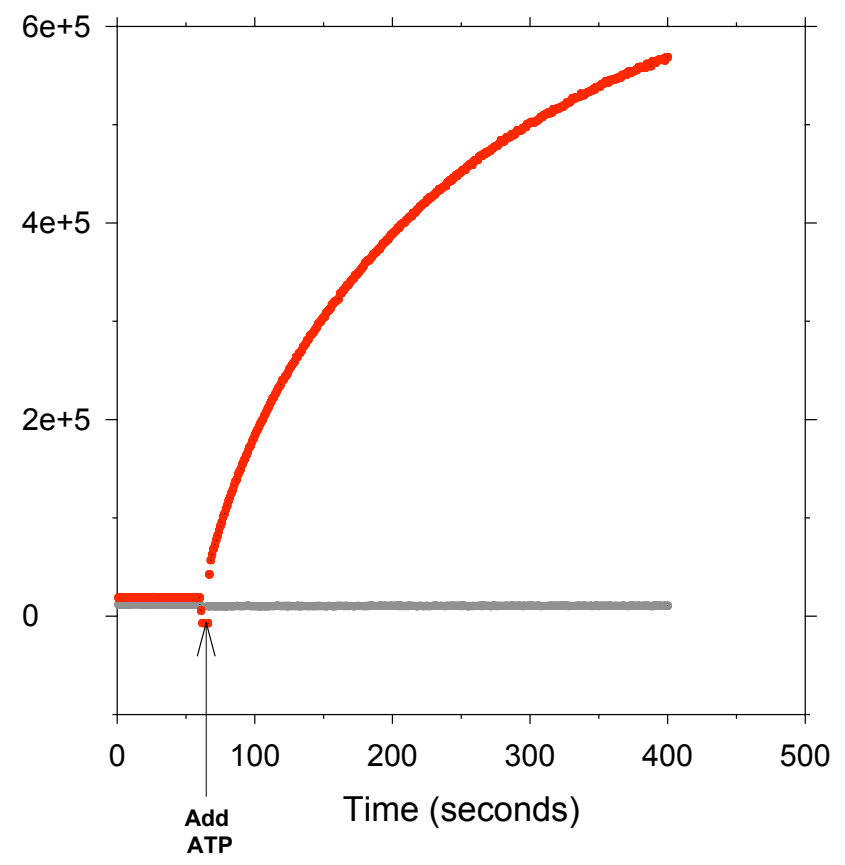


Inhibitor I $\boldsymbol{C}_{50}$ values. $1 \mu \mathrm{M}$ pyrene-labeled peptide substrate $\mathbf{P} 2$ was incubated in $60 \mu \mathrm{M}$

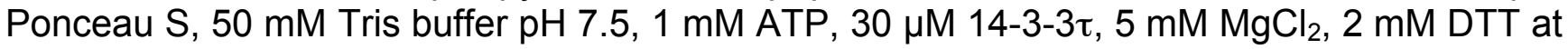
$30{ }^{\circ} \mathrm{C}$ for $5 \mathrm{~min} .10 \mathrm{nM}$ PKA enzyme was added and the reaction progress followed for $1 \mathrm{~min}$. This step was used to adjust for inter-assay variability and to verify that no significant drop in enzyme activity occurs over the course of the determinations. Subsequently, inhibitor was added at different concentrations. Reaction rates were measured under conditions where less than $10 \%$ substrate had been converted to product. Fractional velocities $\left(v / v_{0}\right)$ were plotted against inhibitor concentration [I] and fit using the Sigma Plot version 8.02 software's four-parameter logistic nonlinear regression analysis. PKI (14-22) exhibits an $I C_{50}$ value of 1.1 $\pm 0.1 \mu \mathrm{M}$. The $I C_{50}$ value of PKI (14-22) using the standard radioactive ATP method is $1.6 \pm$ $0.2 \mu \mathrm{M}$. H9. HCl exhibits an $I C_{50}$ value of $42 \pm 1 \mu \mathrm{M}$ at $1 \mathrm{mM}$ ATP and a value of $1.9 \pm 0.2 \mu \mathrm{M}$ at $10 \mu \mathrm{M}$ ATP.

Figure S5. Fractional PKA activity versus log [inhibitor] for (A) $\mathrm{H} 9 \cdot \mathrm{HCl}$ at $10 \mu \mathrm{M} \mathrm{ATP},(B)$ $\mathrm{H} 9 \cdot \mathrm{HCl}$ at $1 \mathrm{mM}$ ATP, (C) PKI (14-22) using Deep Quench method, (D) PKI (14-22) using the standard radioactive ATP method.
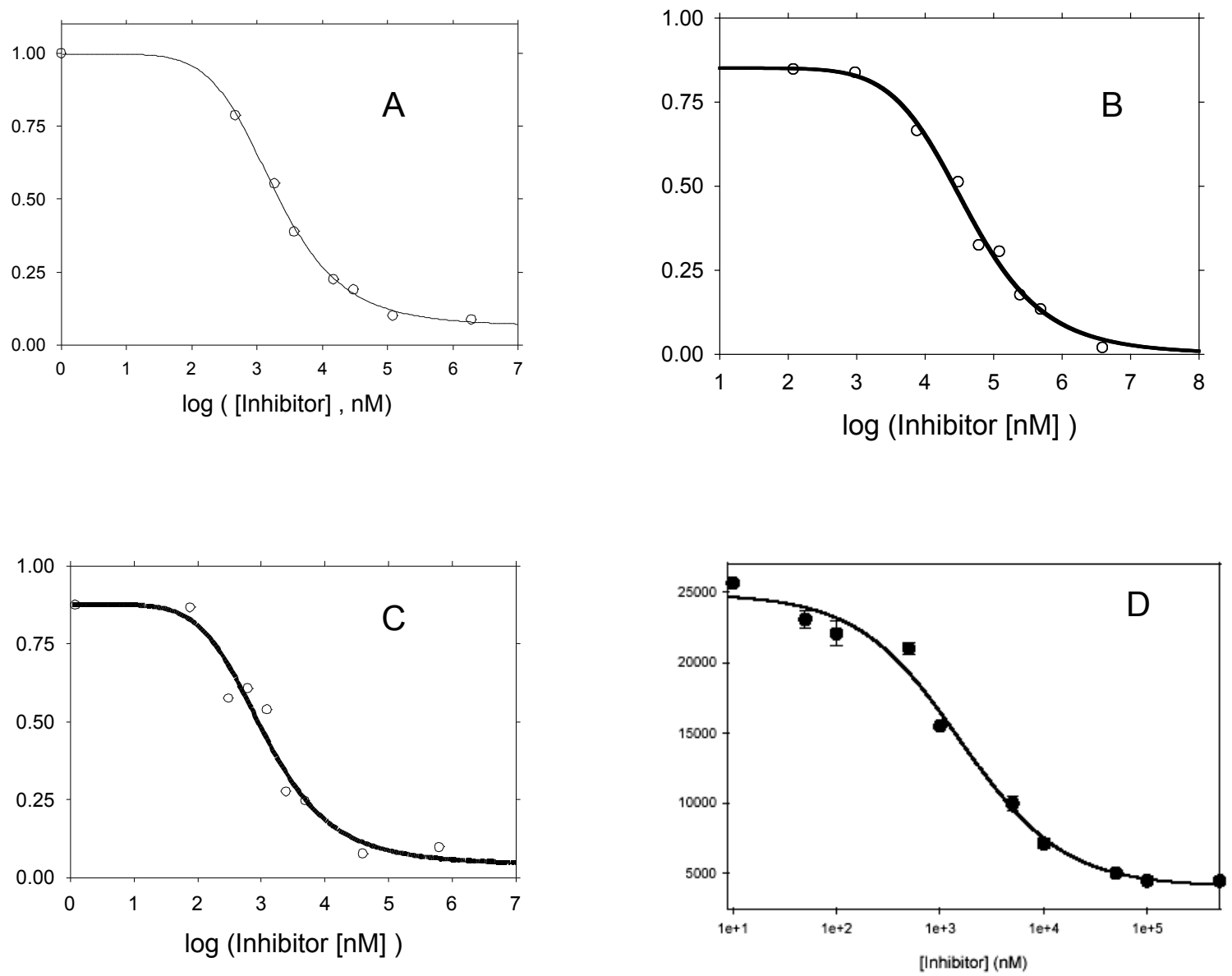
Fluorescence change dependency on instrumentation/reading mode. We have found that the phosphorylation-induced fluorescence change is dependent upon instrumentation and reading mode. In brief, the least dramatic changes are observed in a plate reader (Molecular Devices Spectra Max Gemini EM) using the bottom read mode (i.e. from below through the bottom of a Hellma black quartz 96 well plate. Note: analogous results were obtained using a Costar 3631 flat bottom 96 multiwell plate). A more robust change is obtained via a top read mode with the Hellma black quartz 96 well plate (analogous results were obtained using a Wallac B \& W isoplate 1450-582). The highest fluorescence fold change is provided using a dedicated spectrofluorimeter (Photon Technology QM-1) and a quartz cuvette as the sample holder. These results are summarized in Table S4 for the three lead peptide/quencher pairs. Initial screening of the library of peptides P1 - P11 with the ten lead quenchers (Chart S1) was performed using the bottom read mode. A summary of these results is furnished in Figure S6.

An example of assay conditions in plate reader mode is furnished for the top read with peptide P5 and Rose Bengal: Phosphorylation-dependent increase in pyrene fluorescence intensity of peptide dye pair P5/Rose Bengal, was monitored on a Molecular Devices Spectra Max EM plate reader at $30{ }^{\circ} \mathrm{C}$ using $343 \mathrm{~nm}$ excitation wavelength, $390 \mathrm{~nm}$ emission wavelength. Three wells containing $5 \mu \mathrm{M}$ pyrene-labeled peptide substrate P5 were preincubated in $5 \mathrm{mM} \mathrm{MgCl}$, $2 \mathrm{mM}$ DTT, $1 \mathrm{mM} \mathrm{ATP}$, and $50 \mathrm{mM}$ Tris buffer pH 7.5, $30 \mu \mathrm{M}$ 14-3$3 \tau$ and $25 \mu \mathrm{M}$ Rose Bengal, at $30{ }^{\circ} \mathrm{C}$ for $10 \mathrm{~min} .0 .7 \mu \mathrm{M}$ PKA was added and the reaction progress followed. Three additional wells containing all the assay components except for P5 peptide were used for blank readings. Note: for bottom read multiwell plate mode and single read cuvette mode a $343 \mathrm{~nm}$ excitation wavelength and $380 \mathrm{~nm}$ emission wavelength was employed. 
Table S4. Phosphorylation-induced fluorescence fold-change of lead peptide/quencher pairs as a function of instrumentation, plate $(P=$ plastic and $Q=$ quartz $)$, and read mode.

\begin{tabular}{|c|c|c|}
\hline Peptide/Quencher (ratio) & Conditions & Fluorescence Change \\
\hline \multirow{3}{*}{ P2/ Ponceau S (1:50) } & $\begin{array}{l}\text { Plate reader }(P) \text { - bottom read } \\
\text { Plate reader }(Q) \text { - bottom read }\end{array}$ & $\begin{array}{l}\text { 7-fold } \\
6 \text {-fold }\end{array}$ \\
\hline & $\begin{array}{l}\text { Plate reader }(P) \text { - top read } \\
\text { Plate reader }(Q) \text { - top read }\end{array}$ & $\begin{array}{l}15 \text {-fold } \\
7 \text {-fold }\end{array}$ \\
\hline & spectrofluorimeter & 21-fold \\
\hline \multirow{3}{*}{ P5/Rose Bengal (1:5) } & $\begin{array}{l}\text { Plate reader }(P) \text { - bottom read } \\
\text { Plate reader }(Q) \text { - bottom read }\end{array}$ & $\begin{array}{l}\text { 8-fold } \\
\text { 24-fold }\end{array}$ \\
\hline & $\begin{array}{l}\text { Plate reader }(P) \text { - top read } \\
\text { Plate reader }(Q) \text { - top read }\end{array}$ & $\begin{array}{l}30 \text {-fold } \\
33 \text {-fold }\end{array}$ \\
\hline & spectrofluorimeter & 64-fold \\
\hline \multirow{3}{*}{ P9/Aniline Blue WS (1:10) } & $\begin{array}{l}\text { Plate reader }(P) \text { - bottom read } \\
\text { Plate reader }(Q) \text { - bottom read }\end{array}$ & $\begin{array}{l}\text { 9-fold } \\
\text { 13-fold }\end{array}$ \\
\hline & $\begin{array}{l}\text { Plate reader }(P) \text { - top read } \\
\text { Plate reader }(Q) \text { - top read }\end{array}$ & $\begin{array}{l}19 \text {-fold } \\
28 \text {-fold }\end{array}$ \\
\hline & spectrofluorimeter & 55-fold \\
\hline
\end{tabular}


Figure S6. PKA-induced fluorescence change of peptide $\mathbf{P 1}-\mathbf{P} 11$ in the presence of the ten lead quencher dyes. Peptide concentration was fixed at $5 \mu \mathrm{M}$ and a 5-, 10-, 25-, and 50-fold excess of quencher was employed. Color scheme: light green ( 1.5 to $<3$-fold change), yellow ( $3<$ to $<4.8$-fold change), peach $(4.8<$ to $<6$-fold change), orange $(6<$ to $<8$-fold change), and red (8-fold change and above).

\begin{tabular}{|c|c|c|c|c|c|c|c|c|c|c|c|c|c|}
\hline & \multirow[b]{2}{*}{ Fold } & \multirow[b]{3}{*}{ P1 } & \multirow[b]{3}{*}{$\mathrm{P} 2$} & \multirow[b]{3}{*}{ P3 } & \multirow[b]{3}{*}{ P4 } & \multirow[b]{3}{*}{ P5 } & \multirow[b]{3}{*}{ P6 } & \multirow[b]{3}{*}{ P7 } & \multirow[b]{3}{*}{$\mathrm{P} 8$} & \multirow[b]{3}{*}{ P9 } & \multirow[b]{3}{*}{ P10 } & \multirow[b]{3}{*}{ P11 } & \\
\hline & & & & & & & & & & & & & \\
\hline & excess dye & & & & & & & & & & & & \\
\hline & 50 & 1.15 & 0.94 & 0.99 & 0.91 & 0.78 & 0.70 & 0.81 & 0.88 & 0.83 & 0.73 & 0.74 & \\
\hline D3 & 25 & 1.46 & 1.01 & 1.06 & 0.89 & 0.84 & 0.06 & 0.45 & 0.89 & 0.26 & 0.59 & 0.25 & \\
\hline \multirow[t]{2}{*}{ Evans Blue } & 10 & 1.43 & 1.37 & 1.06 & 0.91 & 0.92 & 0.74 & 0.31 & 0.36 & 0.24 & 0.64 & 0.12 & \\
\hline & 5 & 1.69 & 1.92 & 1.10 & 0.98 & 1.33 & 1.50 & 1.01 & 1.34 & 1.09 & 0.69 & 0.46 & \\
\hline & 50 & 3.85 & 6.30 & 1.68 & 4.27 & 5.79 & 4.70 & 5.20 & 5.01 & 4.03 & 3.48 & 2.46 & \\
\hline \multirow{3}{*}{$\begin{array}{l}\text { D6 } \\
\text { Reactive Blue }\end{array}$} & 25 & 2.92 & 5.66 & 3.56 & 3.55 & 6.44 & 4.78 & 4.43 & 5.33 & 4.95 & 3.95 & 3.09 & \\
\hline & 10 & 1.57 & 2.08 & 2.29 & 2.66 & 3.99 & 2.33 & 3.68 & 3.40 & 3.61 & 3.80 & 1.72 & \\
\hline & 5 & 1.00 & 1.99 & 1.48 & 2.16 & 2.28 & 1.63 & 2.64 & 2.57 & 3.39 & 5.12 & 1.57 & \\
\hline & 50 & 1.10 & 3.71 & 0.31 & 0.59 & 1.12 & 1.52 & 0.48 & 0.45 & 0.65 & 0.72 & 0.30 & \\
\hline \multirow{3}{*}{$\begin{array}{l}\text { D18 } \\
\text { Eriochrome Black T }\end{array}$} & 25 & 0.41 & 1.13 & 0.58 & 0.59 & 0.84 & 0.87 & 1.58 & 0.62 & 1.46 & 0.79 & 0.56 & \\
\hline & 10 & 1.13 & 1.42 & 1.02 & 1.12 & 1.73 & 1.37 & 1.64 & 1.47 & 1.52 & 2.23 & 0.71 & \\
\hline & 5 & 0.96 & 1.46 & 1.10 & 1.32 & 1.61 & 1.37 & 1.82 & 1.65 & 2.09 & 2.51 & 1.42 & \\
\hline & 50 & 1.13 & 1.30 & 1.05 & 1.07 & 1.50 & 1.27 & 1.34 & 1.64 & 2.03 & 2.44 & 1.14 & \\
\hline \multirow{3}{*}{$\begin{array}{l}\text { D19 } \\
\text { Alizarin Red }\end{array}$} & 25 & 1.01 & 1.37 & 1.17 & 1.23 & 1.49 & 1.32 & 1.60 & 1.59 & 1.91 & 1.95 & 1.28 & \\
\hline & 10 & 0.96 & 1.38 & 1.21 & 1.33 & 1.59 & 1.27 & 1.63 & 1.57 & 1.98 & 1.90 & 1.35 & \\
\hline & 5 & 0.98 & 1.59 & 1.28 & 1.36 & 1.70 & 1.35 & 1.71 & 1.68 & 2.01 & 1.97 & 1.31 & \\
\hline & 50 & 1.55 & 1.83 & 0.99 & 1.40 & 1.23 & 1.28 & 1.39 & 1.35 & 1.28 & 1.09 & 1.63 & \\
\hline \multirow{3}{*}{$\begin{array}{l}\text { D27 } \\
\text { Aniline Blue WS }\end{array}$} & 25 & 4.13 & 2.52 & 3.79 & 5.58 & 6.04 & 5.60 & 4.76 & 1.81 & 3.59 & 2.39 & 2.21 & \\
\hline & 10 & 0.47 & 2.48 & 2.17 & 4.82 & 5.36 & 3.48 & 6.63 & 6.22 & 8.94 & 6.77 & 1.78 & \\
\hline & 5 & 1.16 & 1.85 & 1.50 & 2.34 & 3.02 & 2.35 & 3.85 & 4.07 & 6.22 & 6.82 & 1.62 & \\
\hline \multirow{4}{*}{$\begin{array}{l}\text { D34 } \\
\text { Chlorazol Black E }\end{array}$} & 50 & 0.10 & 0.35 & 0.25 & 0.87 & 0.25 & 0.38 & 0.95 & 0.97 & 0.85 & 0.89 & 0.19 & \\
\hline & 25 & 0.49 & 0.60 & 0.92 & 0.55 & 0.21 & 1.10 & 1.08 & 1.05 & 0.88 & 0.74 & 0.86 & \\
\hline & 10 & 2.44 & 2.84 & 0.71 & 0.93 & 1.52 & 2.32 & 2.49 & 2.83 & 1.61 & 1.32 & 0.83 & \\
\hline & 5 & 1.42 & 2.26 & 1.79 & 4.01 & 5.62 & 2.27 & 4.81 & 6.65 & 3.63 & 4.80 & 1.62 & \\
\hline \multirow{4}{*}{$\begin{array}{l}\text { D42 } \\
\text { Ponceau S }\end{array}$} & 50 & 3.37 & 6.57 & 2.88 & 2.69 & 4.36 & 1.77 & 1.27 & 3.26 & 4.02 & 2.81 & 2.38 & \\
\hline & 25 & 1.84 & 4.61 & 2.75 & 2.88 & 3.23 & 3.13 & 2.19 & 2.01 & 4.64 & 5.66 & 2.12 & \\
\hline & 10 & 1.76 & 1.92 & 2.26 & 2.63 & 3.30 & 3.36 & 1.92 & 3.86 & 4.83 & 7.99 & 2.06 & \\
\hline & 5 & 1.35 & 1.93 & 1.81 & 2.26 & 2.85 & 2.77 & 2.00 & 3.14 & 4.32 & 7.56 & 2.10 & \\
\hline & 50 & 0.96 & 0.72 & 0.97 & 0.91 & 0.95 & 0.94 & 0.85 & 0.95 & 0.98 & 0.89 & 0.84 & \\
\hline D43 & 25 & 1.03 & 1.58 & 1.13 & 1.10 & 1.02 & 1.20 & 0.85 & 0.81 & 1.11 & 1.23 & 0.32 & \\
\hline Rose Bengal (Cert) & 10 & 2.63 & 2.87 & 1.98 & 2.88 & 3.45 & 3.28 & 1.12 & 2.19 & 1.85 & 1.32 & 0.94 & \\
\hline & 5 & 1.20 & 2.58 & 2.70 & 6.52 & 8.36 & 2.71 & 7.44 & 5.43 & 3.51 & 3.26 & 3.54 & \\
\hline & 50 & 1.31 & 2.51 & 1.02 & 1.47 & 2.05 & 1.25 & 1.65 & 1.79 & 1.53 & 1.92 & 1.43 & \\
\hline D47 & 25 & 1.16 & 1.82 & 1.47 & 1.46 & 1.79 & 1.42 & 1.77 & 1.58 & 1.82 & 1.76 & 1.28 & \\
\hline Tartrazine & 10 & 1.06 & 1.61 & 1.34 & 1.42 & 1.52 & 1.27 & 1.55 & 1.47 & 1.57 & 1.64 & 1.17 & \\
\hline & 5 & 0.99 & 1.41 & 1.19 & 1.28 & 1.43 & 1.23 & 1.46 & 1.39 & 1.55 & 1.47 & 1.15 & \\
\hline D48 & 50 & 2.60 & 6.03 & 1.60 & 2.76 & 3.48 & 3.34 & 5.62 & 3.52 & 2.62 & 3.39 & 3.17 & \\
\hline Trypan Blue & 25 & 3.40 & 5.11 & 1.91 & 1.72 & 3.61 & 3.05 & 4.10 & 4.03 & 3.67 & 3.53 & 2.45 & \\
\hline & 10 & 3.04 & 2.81 & 2.72 & 2.18 & 2.72 & 2.17 & 4.76 & 4.87 & 3.96 & 3.45 & 3.40 & \\
\hline & 5 & 1.30 & 2.20 & 2.23 & 3.03 & 6.21 & 3.54 & 7.15 & 6.14 & 7.18 & 7.22 & 3.06 & \\
\hline
\end{tabular}


Figure S7. Assay of the cGMP-dependent protein kinase (PKG). P2 peptide (10 $\mu \mathrm{M}$ ) was pre-

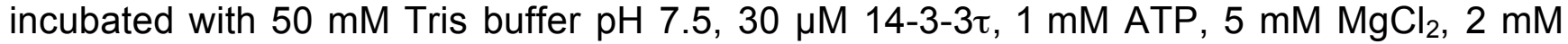
DTT, $60 \mu \mathrm{M}$ Ponceau S dye with (red) and without (green) cGMP $(1 \mathrm{mM})$ at $30^{\circ} \mathrm{C}$ for $10 \mathrm{~min}$. After $2 \mathrm{~min}$, PKG (90 nM) was added and the reaction progress monitored. The initial rate $v_{0}$, (obtained from the $300-400 \mathrm{~s}$ interval of the progress-curve), is 8.2 fold faster in the presence than in the absence of cGMP.

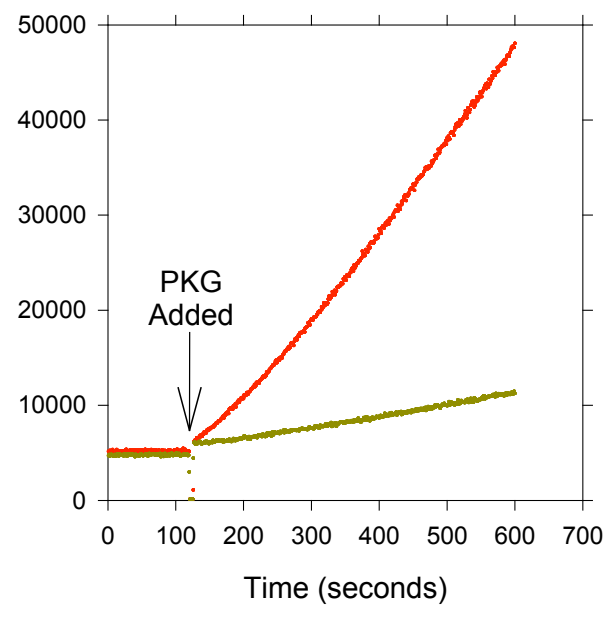


Figure S8. Effect of quencher on enzyme reaction rate. PKA concentration required to convert all substrate to product in $30 \mathrm{~min}$ is dependent upon the apparent $K_{d}$ of quencher and substrate. The stronger the interaction between quencher and substrate the more enzyme required to achieve complete conversion of substrate to product in $30 \mathrm{~min}$. This is consistent with the notion that the negatively charged quencher associates with the positively charged peptide substrate via electrostatic interactions. The positively charged residues on the peptide are required for recognition by PKA.

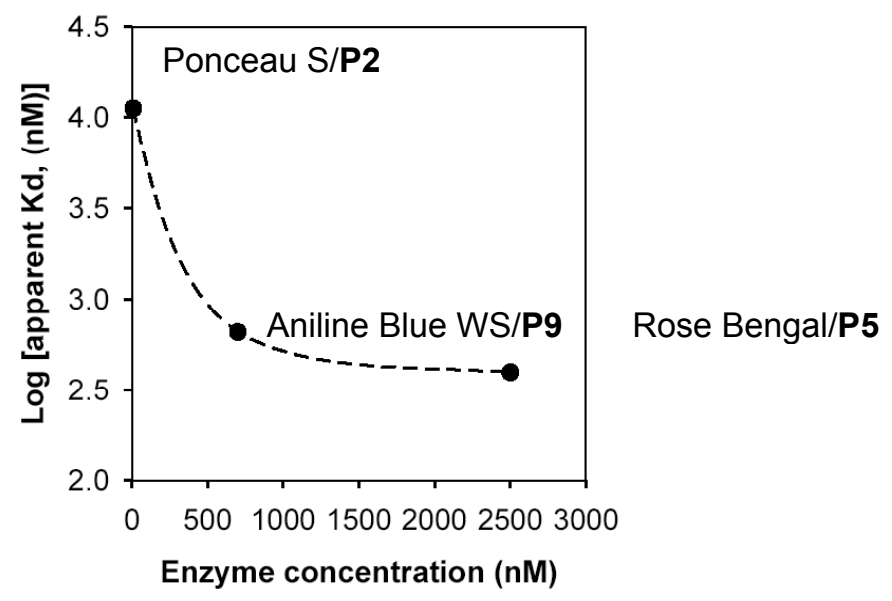

